\title{
Congenital malformations of human dermatoglyphs
}

\author{
T. J. DAVID \\ From the General Hospital, Bristol
}

\begin{abstract}
David, T. J. (1973). Archives of Disease in Childhood, 48, 191. Congenital malformations of dermatoglyphs. A classification for congenital malformations of dermatoglyphs is presented, dividing them into ridge aplasia, ridge hypoplasia, ridge dissociation, ridges-off-the-end, and a combination of the last two. The medical and genetic significance of these are considered in the light both of previous published cases and of new material. Malformations of dermatoglyphs are important as physical signs in paediatric diagnosis.
\end{abstract}

While dermatoglyphs are becoming increasingly important in the study of congenital malformations and as physical signs in paediatric diagnosis, it is not often realized that dermatoglyphs can be malformed per se. Such epidermal ridge pattern malformations usually either pass unrecognized or are abandoned as 'freak' patterns (Cherrill, 1954). In this paper the commonest ridge malformations will be described and a classification presented, but no mention will be made of rare patterns (e.g. lateral pocket loops, composites, nutant loops) which are better described as 'rare' until it can be shown that they are indeed abnormal.

\section{Common ridge malformations}

1. Ridge aplasia. This is a rare malformation consisting of congenital absence of epidermal ridges over the entire palmar and plantar surfaces. The palmar and interphalangeal flexion creases remain normal, but there is a great excess of very small creases on the skin, which appear as 'white lines' on the finger or palm prints. To the naked eye and on the actual fingerprints the skin gives an 'orangepeel' appearance which is characteristic but not by itself diagnostic. The palmar and plantar surfaces do not sweat. Examples of genuine ridge aplasia have been found in an American kindred (Baird, 1964, 1968) when it appeared to be inherited as an autosomal dominant trait. The affected members of this kindred also had transient congenital milia and bilateral flexion contractures of some fingers and toes. However, a 4-year-old girl has been found at this hospital who, in addition to ridge aplasia, suffers from severe dermatological problems at sites distant to the palms and soles, the condition thought to be a generalized disorder

Received 5 July 1972. of keratin production (David and Warin, 1973). Her parents have normal epidermal ridges and normal prints. Reports about 'absent fingerprints' tend to be poorly documented (Ludy, 1944; Rott, 1970a) or show ridges to be present though hypoplastic or dissociated (Cooke, 1962; Holt, 1964; McCann, 1969; Cummins, 1970a, b).

2. Ridge hypolasia. In this condition the ridges are not absent but are reduced in height, and this is often combined with a great excess of 'white lines' on the prints. It can be inherited as an autosomal dominant trait (Furuhata et al., 1957; Basan, 1965). Congenital ridge hypoplasia in an individual is impossible to distinguish from the acquired condition of epidermal ridge atrophy. The latter is a partly reversible change found in extreme old age, in some people with mental subnormality (Matsukura, 1953; Yamashita, 1960), and in 90 to $95 \%$ of adults with coeliac disease (David, Ajdukiewicz, and Read, 1970). Ridge atrophy tends to be less severe than congenital ridge hypoplasia, and the former is an acquired condition which is not itself inherited (though the underlying coeliac disease may well be inherited). The ridge atrophy found in adults with coeliac disease partly improves when a gluten-free diet is instituted (David et al., 1970).

Congenital ridge hypoplasia is sometimes present in patients with chromosome abnormalities, particularly those with autosomal aneuploidies. Under these conditions the ridge hypolasia is usually a patchy change most commonly involving the proximal regions of the palms and soles, and can make observation of the dermatoglyphs extremely difficult at a time when they may be most useful as physical signs. Though this kind of ridge hypoplasia is congenital, some improvement can take place by 


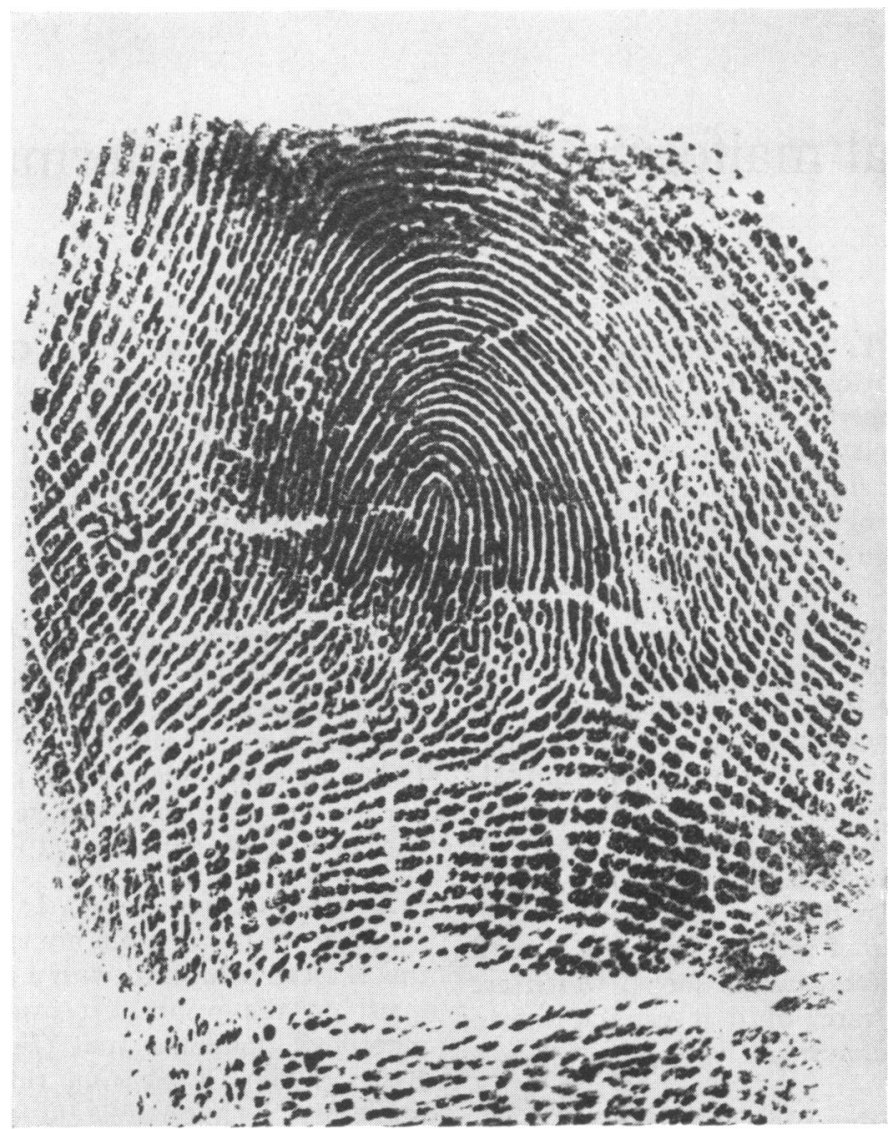

FIG. 1.-Mild ridge dissociation in the left middle finger print, mainly affecting the area of the triradius as well as below the core of the pattern.

growth of the hypoplastic ridges. It is worth mentioning that ridge hypoplasia can occasionally be found on some palmar and plantar surfaces of congenitally deformed limbs.

3. Ridge dissociation. In this condition, the ridges instead of running neatly in more or less parallel lines, are broken up into short ridges which tend to be curved and are completely disorganized (Nettles, 1963; Cooke, 1960; Cummins, 1967; Safara, 1969). It is most commonly found on the thumbs and in the region of the $t$ triradius on the palm. Whether the $t$ triradius is at its normal position near the wrist or at a $t^{\prime \prime}$ position in the centre of the palm makes no difference; it is still the commonest site for ridge dissociation on the palm. The distribution of ridge dissociation is absolutely characteristic on the fingers. The thumb is the commonest digit to be affected, followed by the index, middle, ring, and little fingers, the lesion becoming progressively less in this order. When the ridge dissociation is mild it always affects the region of the fingerprint just below the core of the pattern (Fig. 1) (Cummins, 1968, 1970c), and this is a good distinguishing feature. The lesion can be so mild as to affect only a small area around the $t$ triradius, or so gross that the entire palmar and plantar surfaces are covered with dissociated ridges, with complete loss of ridge patterns as a consequence (Fig. 2). As in ridge aplasia, the palmar and interphalangeal flexion creases are normal.

Ridge dissociation is a heterogeneous condition. It can be inherited as an autosomal dominant trait (Furuya, 1961, 1967; Dodinval et al., 1971) or it can be sporadic (Furuhata and Kawashima, 1950). One family has been reported where ridge dissociation was associated with tapering fingers, painful fingertips, and a minor nail dystrophy (Dodinval, 1972). The suggestion that ridge dissociation is 




Fig. 2.-Left palm print showing gross ridge dissociation of the whole palm with no discernible triradii or patterns.

often associated with tapering fingers and a nail dystrophy (Dodinval, 1971) is neither evident from the literature nor from the families with ridge dissociation studied in the south west of England by the author. Nevertheless, it is logical to look for other ectodermal defects, and ridge dissociation has been observed by the author in one patient with hypohidrotic ectodermal dysplasia.

True ridge dissociation is sometimes mistaken for an area of scarring, and vice versa. It has been said that ridge dissociation is present in $18 \%$ of schizophrenics (Raphael and Raphael, 1962), but both the published examples of ridge dissociation were typical of injuries which had healed by granulation, most probably burns (David, 1969). To distinguish between mild ridge dissociation only on the thumbs and scars healed by granulation is always difficult, and is best left to an experienced observer who has seen many examples of ridge dissociation. The principal differences are outlined in the Table.

Other studies of dermatoglyphs in schizophrenia have not revealed an increased incidence of ridge dissociation (Sank, 1968; Mellor, 1968; Zavala and Núñez, 1970; Rothhammer et al., 1971), and the author has had the opportunity to examine the palmar dermatoglyphs of 600 patients with schizophrenia kindly lent by Dr. A. Pauline Ridges in Liverpool. There was not one example of ridge dissociation.

Out of 430 patients with congenital heart disease 
TABLE

Differences between ridge dissociation and burn scars

\begin{tabular}{|c|c|c|}
\hline & Ridge dissociation & Burn scars \\
\hline Commonest digit & Thumb & $\begin{array}{l}\text { Index and little } \\
\text { fingers (Cherrill, } \\
\text { 1954) }\end{array}$ \\
\hline $\begin{array}{l}\text { Area of fingerprint } \\
\text { pattern first affected }\end{array}$ & Below core & Any area \\
\hline $\begin{array}{l}\text { Proximal phalanges } \\
\text { affected }\end{array}$ & Not described & Possible \\
\hline $\begin{array}{l}\text { Area of palm first } \\
\text { affected }\end{array}$ & $t$ triradius & Any area \\
\hline $\begin{array}{l}\text { Affected digits }+ \\
\text { normal thumbs }\end{array}$ & Probably never & Often \\
\hline Toes affected & $\begin{array}{l}\text { Common if fingers } \\
\text { affected }\end{array}$ & Rare \\
\hline Incidence & ? 1 in 8000 & $\begin{array}{l}\text { About } 1 \% \\
\quad(\text { Cherrill, 1954) }\end{array}$ \\
\hline
\end{tabular}

studied in Bristol, 2 have ridge dissociation. One has multiple cardiac abnormalities with no family history of congenital heart disease, and his parents and 4 sibs have normal prints. The other has a truncus arteriosus with atrial and ventricular septal defects as well as a hare lip. His only sib has a normal heart and normal prints, but his father has marked ridge dissociation and also has bilateral polythelia with a normal heart. Some of the father's relatives also have ridge dissociation, the distribution of affected members fitting with autosomal dominant inheritance. The author has been able to examine the prints of a pair of monozygotic twins who were concordant for a rare dental abnormality (of unestablished aetiology) as well as for ridge dissociation. There is no family history of the dental condition, and the parents do not have ridge dissociation. It is likely that these are chance associations, and the author has also seen ridge dissociations in several sporadic cases where there were no detectable birth defects.

Ridge dissociation of a slightly different type is often found in patients with chromosome abnormalities, and also some patients with the de Lange syndrome (Berg et al., 1970) (Fig. 3). The ridges are broken up regularly into dots and the patterns are obscured (Wolf et al., 1965). A mild appearance of 'dotted ridges', when the patterns remain quite clear (Fig. 4), is easily visible in the prints of at least $80 \%$ of patients with mongolism (trisomy-21), but oddly it is never included in complex dermatoglyphic discriminant functions for this diagnosis. Similar mild ridge dissociation has been reported in 7 out of 20 cases with trisomy-18 and in 12 out of 20 cases with $\mathrm{D}^{1}$-trisomy (Taylor, 1968). A more severe form of the 'dotted ridges' variant of ridge dissociation was reported in a trisomy-18/normal mosaic (Alter and Schulenberg, 1967). The ridge

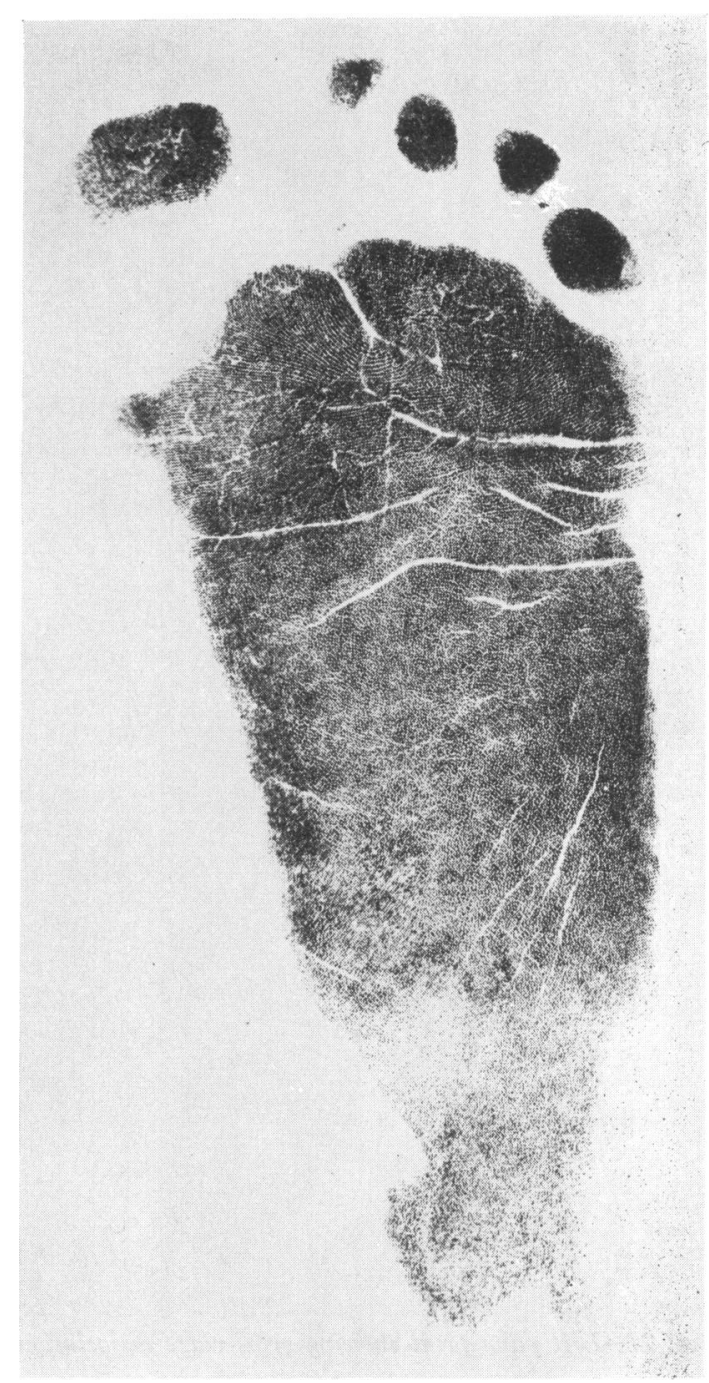

FIG. 3.-Right sole print of a boy with the de Lange syndrome, showing the 'dotted ridges' kind of ridge dissociation seen in this condition. Note that the lesion is worse proximally, and over the hallucal area the ridges are normal.

dissociation found in patients with chromosome abnormalities is likely to be a nonspecific effect of abnormal growth in utero rather than a direct genetic effect. 'Dotted ridges' can be found in normal people when it can be a fully reversible change. It has been noted in some patients with cystic fibrosis (Schwanitz and Rott, 1970), and the author has seen it completely disappear over a period of 6 months in a 20-year-old girl with small intestinal pseudo-obstruction (Fig. 4). 
Fig. 4.- 'Dotted ridges' in a 20-year-old girl with small intestinal pseudoobstruction. Prints of both thumbs are shown. Note that the pattern is in no way obscured (compare with Fig. 3).
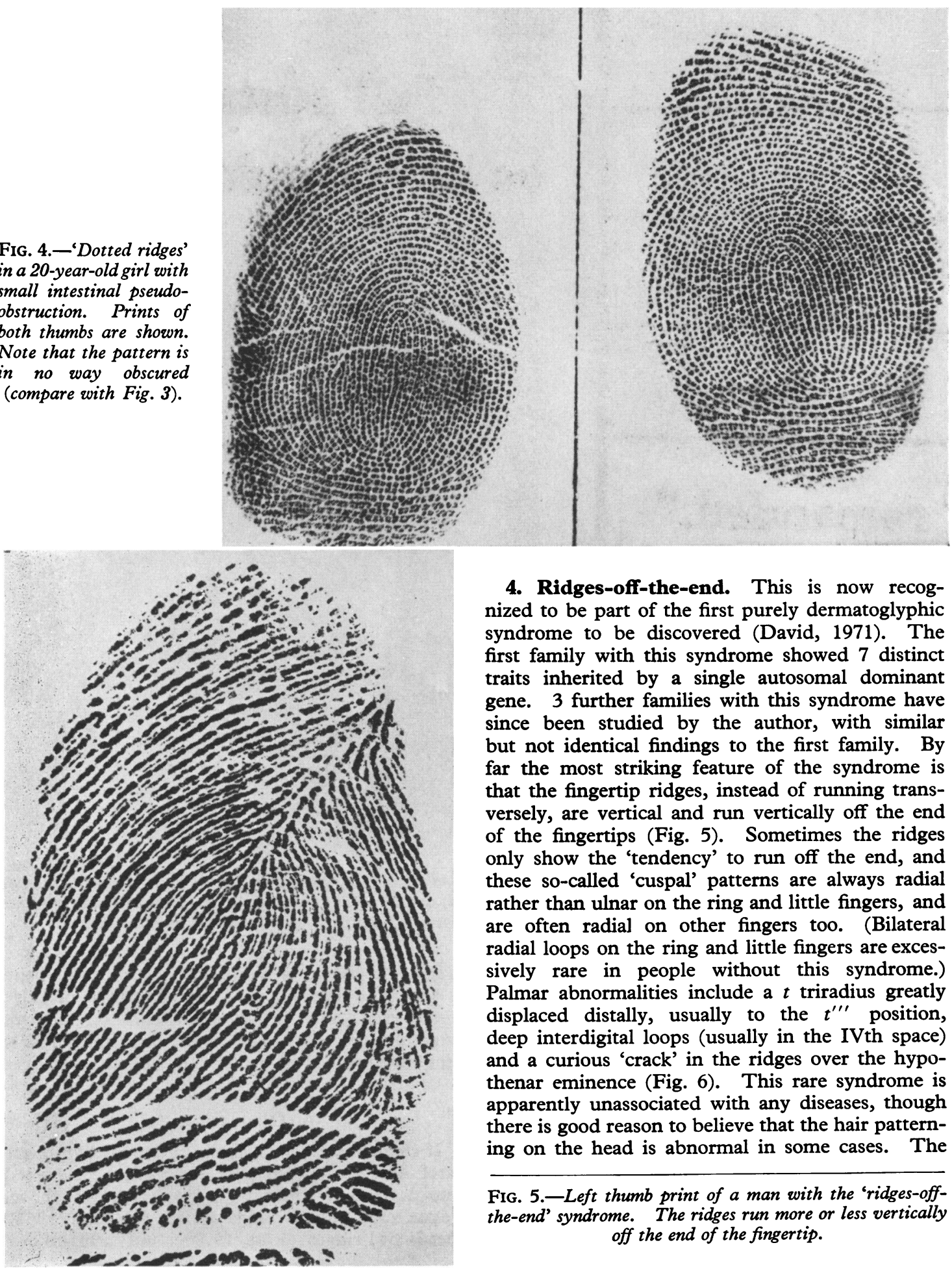

4. Ridges-off-the-end. This is now recognized to be part of the first purely dermatoglyphic syndrome to be discovered (David, 1971). The first family with this syndrome showed 7 distinct traits inherited by a single autosomal dominant gene. 3 further families with this syndrome have since been studied by the author, with similar but not identical findings to the first family. By far the most striking feature of the syndrome is that the fingertip ridges, instead of running transversely, are vertical and run vertically off the end of the fingertips (Fig. 5). Sometimes the ridges only show the 'tendency' to run off the end, and these so-called 'cuspal' patterns are always radial rather than ulnar on the ring and little fingers, and are often radial on other fingers too. (Bilateral radial loops on the ring and little fingers are excessively rare in people without this syndrome.) Palmar abnormalities include a $t$ triradius greatly displaced distally, usually to the $t^{\prime \prime \prime}$ position, deep interdigital loops (usually in the IVth space) and a curious 'crack' in the ridges over the hypothenar eminence (Fig. 6). This rare syndrome is apparently unassociated with any diseases, though there is good reason to believe that the hair patterning on the head is abnormal in some cases. The

FIG. 5.-Left thumb print of a man with the 'ridges-offthe-end' syndrome. The ridges run more or less vertically off the end of the fingertip. 


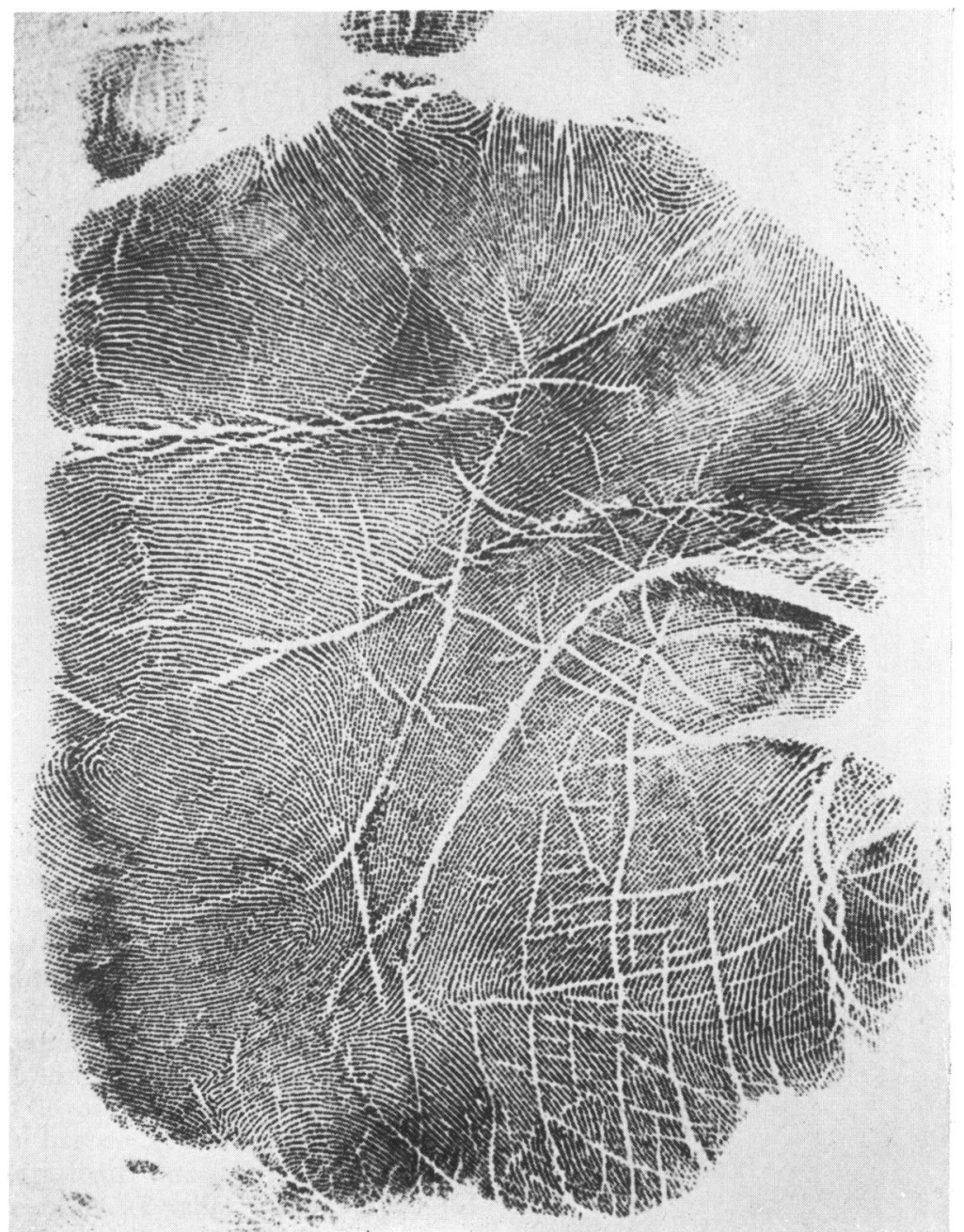

Fig. 6.-Left palm print of a child with the 'ridges-off-the-end' syndrome, showing a bizarre pattern disturbance just above the wrist, a maximal atd angle which is greatly increased, and a 'crack' in the ridges of the hypothenar eminence extending from the lateral part of the hypothenar pattern in a vertical direction towards the little finger.

'ridges-off-the-end' syndrome is easily distinguishable from ridges running vertically off the end of a congenitally deformed digit.

5. Ridges-off-the-end and ridge dissociation. There appear to be only two known examples of this rather unique combination. One was unwittingly published as 'ridge hypoplasia' by Matsukura (1953). The other is a member of a Welsh family with ridge dissociation studied by the author. Mild ridge dissociation was segregating as an autosomal dominant in this family, but one member (whose parents were first cousins) had complete ridge dissociation of his palms and soles (his palm is shown in Fig. 2), with a combination of ridge dissociation and ridges-off-the-end on all his fingertips (Fig. 7). The family was intellectually dim but there was no evidence of associated disease.

\section{Discussion}

If congenital malformations of dermatoglyphs are carefully studied then they can easily be classified into at least 5 distinct groups as shown above. Vague terms such as 'ridge disruption' (Alter, 1967), 'bead-cord ridges' (Rott, 1970b), and 'pearl-ridges' 


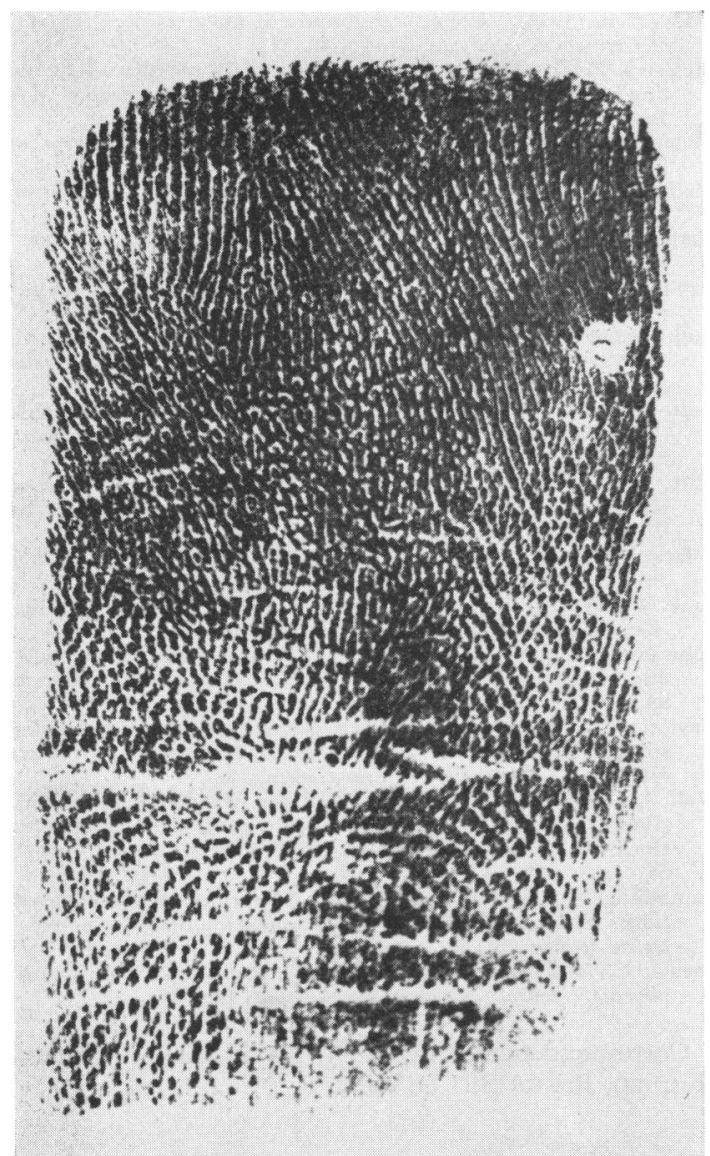

FIG. 7.-Left ring finger print, showing a combination of severe ridge dissociation and also ridges running vertically off the end.

(Schwanitz and Rott, 1970) should be abandoned. 'Ridge dysplasia' is a vague concept that probably covers all the abnormalities described in this paper; it is a loose term to be avoided.

The first 4 malformations listed in this paper, ridge-aplasia, ridge hypoplasia, ridge dissociation, and ridges-off-the-end, have one feature in common: that is, they can all be inherited as an autosomal dominant gene. While ring constrictions can be shown to be aetiologically important in some individuals with ring constrictions of limbs (Abel, 1936) and ridge dissociation in the digits distal to the constriction, this cause can hardly account for the majority of cases of ridge dissociation.

The incidence of these malformations is as yet unknown, partly because none of them is common but mainly because they are usually not correctly recognized. Ridge hypoplasia secondary to a chromosome abnormality is the commonest of the malformations, followed by the heterogeneous group of people with ridge dissociation. Ridge aplasia is likely to be genuinely rare, or it would have caused trouble by now for identification purposes. The 'ridges-off-the-end' syndrome was first thought to be excessively rare, but already in 4 years 4 families with this condition have been found in the United Kingdom alone, and there are now good reasons for thinking that it is not so rare after all. It should be mentioned that Abel (1936) found ridge dissociation in 11 out of 8000 'people', some of them criminals and probably mostly males, and that Dodinval et al. (1971) found it in only 2 out of 500,000 people in Belgium. The former figure is derived from people who could hardly be called 'controls', and the latter is likely to be a gross underestimate since these prints were not systematically searched for ridge dissociation. Indeed the second case was only found because he was the son of the first case.

With the wider use of dermatoglyphs as physical signs in paediatric diagnosis, the classification of abnormalities in this paper should help to clarify the importance of congenital malformations of dermatoglyphs. An essential for their recognition is the careful recording of finger, palm, sole, and toe prints.

The author is indebted to the many physicians who have made their patients available for study, and to Professor P. E. Polani and Dr. D. W. Barritt who have reviewed the manuscript. The author is in receipt of grants from the South Western Regional Hospital Board and the United Bristol Hospitals.

\section{REFERENCES}

Abel, W. (1936). Ưber Störungen der Papillarmuster. I. Gestorte Papillarmuster in Verbindung mit einigen körperlichen und geistigen Anomalien. Zeitschrift für Morphologie und Anthropologie, 36, 1 .

Alter, M. (1967). Dermatoglyphic analysis as a diagnostic tool. Medicine, 46, 35.

Alter, M., and Schulenberg, R. (1967). Dysplasia of epidermal ridges in a trisomy $18 /$ normal mosaic. Developmental Medicine and Child Neurology, 9, 582.

Baird, H. W. (1964). Kindred showing congenital absence of the dermal ridges (fingerprints) and associated anomalies. Fournal of Pediatrics, 64, 621.

Baird, H. W. (1968). Absence of fingerprints in four generations. Lancet, 2, 1250.

Basan, M. (1965). Ektodermale Dysplasie. Archiv für klinische und experimentelle Dermatologie, 222, 546.

Berg, J. M., McCreary, B. D., Ridler, M. A. C., and Smith, G. F. (1970). The De Lange Syndrome. Pergamon, Oxford.

Cherrill, F. R. (1954). The Finger Print System at Scotland Yard. H.M.S.O., London.

Cooke, T. D. (1960). Odd IAI convention prints explained. Finger Print and Identification Magazine, 42, No. 6, 15.

Cooke, T. D. (1962). Ridgeless patterns turn up again. Finger Print and Identification Magazine, 44, No. 4, 12.

Cummins, H. (1967). Finger prints: normal and abnormal patterns. Finger Print and Identification Magazine, 49, No. 5, 6. 
Cummins, H. (1968). Harold Cummins comments on unusual prints from New Hampshire. Finger Print and Identification Magazine, 50, No. 3, 11

Cummins, H. (1970a). Untitled article. New York State Identification and Intelligence System Newsletter, February, p. 6.

Cummins, H. (1970b). Some members of N.Y. family lack usual ridge patterns. Finger Print and Identification Magazine, 51, No. $9,4$.

Cummins, H. (1970c). Dr. Cummins comments on odd Jamaican patterns. Finger Print and Identification Magazine, 52, No. 2, 12.

David, T. J. (1969). Dermatoglyphics in schizophrenia. British Fournal of Psychiatry, 115, 251.

David, T. J. (1971). 'Ridges-off-the-end'-a dermatoglyphic syndrome. Human Heredity, 21, 39.

David, T. J., Ajdukiewicz, A. B., and Read, A. E. (1970). Fingerprint changes in coeliac disease. British Medical fournal, 4, 594.

David, T. J., and Warin, R. P. (1973). Diffuse dyskeratosis with recurrent infections and congenital absence of fingerprints. (In preparation.)

Dodinval, P. (1971). Altérations monogéniques des dermatoglyphes. In Abstracts of the 4th International Congress of Human Genetics, Paris. Excerpta Medica, Amsterdam.

Dodinval, P. (1972). A propos de la dysplasie des crêtes épidermiques. Mise en évidence d'une dysplasie apicale des doigts. Humangenetik, 15, 20.

Dodinval, P., Leblanc, P., Delree, C., and Deslypere, P. (1971). Dysplasie des crêtes épidermiques, à hérédité dominante autosomique. Etude des dermatoglyphes d'une famille. Humangenetik, 11, 230.

Furuhata, T., Furuya, Y., Tanaka, T., and Nakajima, H. (1957). A family with unclassifiable papillary patterns. Proceedings of the fapan Academy, 33, 410.

Furuhata, T., and Kawashima, N. (1950). A mysterious man, who has no classifiable papillar ridge pattern on fingers and toes. Proceedings of the Japan Academy, 26, 41.

Furuya, Y. (1961). Genetics of patternless finger dermatoglyph. fapanese fournal of Human Genetics, 6, 102.

Furuya, Y. (1967). A family showing the partial dot-and-shortridge dermatoglyphic patterns in three successive generations. Japanese fournal of Legal Medicine, 21, 114.

Holt, S. B. (1964). Congenital absence of dermal ridges. Developmental Medicine and Child Neurology, 6, 519.
Ludy, J. B. (1944). Congenital absence of fingerprints. Archives of Dermatology and Syphilology, 49, 373

McCann, P. D. (1969). Six Cazenova family members have no finger or palm prints. New York State Identification and Intelligence System Newsletter, December, p. 1.

Matsukura, T. (1953). On the hypoplastic papillary patterns of finger. Nippon Hoigaku Zasshi, 7, 290.

Mellor, C. S. (1968). Dermatoglyphics in schizophrenia. British, fournal of Psychiatry, 114, 1387.

Nettles, J. C. (1963). Dissociated ridges turn up in Alabama. Finger Print and Identification Magazine, 45, No. 6, 24.

Raphael, T., and Raphael, L. G. (1962). Fingerprints in schizophrenia. Fournal of the American Medical Association, 180, 215.

Rothhammer, F., Pereira, G., Camousseight, A., and Benado, M. (1971). Dermatoglyphics in schizophrenic patients. Human Heredity, 21, 198.

Rott, H.-D. (1970a). Vollständige Hautleistenaplasie bei Progerie (Hutchinson-Gilford-Syndrom). Acta Medica Auxologica, $2,125$.

Rott, H.-D. (1970b). Hautleistenstörungen bei verschiedenen Krankheiten. In Hautleisten und Krankheiten, II. Ed. by W. Hirsch. Kolloquium, Berlin.

Safara, U. (1969). Dissociated ridge patterns in Ethiopia. Finger Print and Identification Magazine, 51, No. 3, 7.

Sank, D. (1968). Dermatoglyphics of childhood schizophrenia. Acta Genetica et Statistica Medica, 18, 300.

Schwanitz, G., and Rott, H.-D. (1970). Chromosomenbefunde und Hautleisten bei Mukoviskidose. Fortschritte der Medizin, 88, 194.

Taylor, A. I. (1968). Autosomal trisomy syndromes: a detailed study of 27 cases of Edwards' syndrome and 27 cases of Patau's syndrome. Fournal of Medical Genetics, 5, 227.

Wolf, U., Brehme, H., Baitsch, H., Künzer, W., and Reinwein, H. (1965). Vollstăndige Aplasie des Hautleistensystems bei einem Fall von Mongolismus (G-Trisomie). Homo, Suppl. 66.

Yamashita, N. (1960). On the aberrant formation of epidermal ridges of fingers and toes in feebleminded children. Anthropological Reports, 35, 1.

Zavala, C., and Núñez, C. (1970). Dermatoglyphics in schizophrenia. Fournal de Génétique Humaine, 18, 407.

Correspondence to Dr. T. J. David, Bristol General Hospital, Bristol BS1 6SY. 